Finisterra, XXXVII, 74, 2002, pp. 151-160

\title{
A UTILIZAÇÃO DE BALÕES CATIVOS PARA O ESTUDO MICROCLIMÁTICO DO BAIRRO LISBOETA DE TELHEIRAS
}

ANTÓNIO LOPES ${ }^{1}$

Hugo VIEIRA ${ }^{2}$

\begin{abstract}
Resumo - Nos últimos anos foram realizados vários estudos de climatologia urbana nas cidades portuguesas, recorrendo-se frequentemente a dados obtidos em campanhas de medição itinerantes. O lançamento de balões cativos com aparelhos registadores leves e de baixo custo é uma forma eficiente de conhecer a estrutura térmica urbana. Este método pode ajudar a aplicar os resultados a outras áreas com a mesma morfologia urbana e pode também servir de incentivo à incorporação do conhecimento sobre o clima no planeamento urbano. Os primeiros resultados numa rua do bairro lisboeta de Telheiras são apresentados nesta nota.
\end{abstract}

Palavras-chave : Balões cativos; perfis térmicos; «canhão urbano»; planeamento urbano.

\begin{abstract}
THERMal profiles in URBan CANYONS MEASURED With CAPTIVE BALloONS IN THE LisBon District of TElheiras - Captive balloons filled with standard helium and tinytalks (small low price thermal sensors/data loggers) are an effective way to probe the urban atmosphere for microclimatological purposes. This method can be important to establish the transferability of results to other areas with the same urban morphology and can be also an incentive to incorporate urban climate knowledge in urban planning. The first results in an urban canyon in the north of Lisbon are presented.
\end{abstract}

Key words: Captive balloons; thermal profiles; urban canyons; urban planning.

1 Investigador do Centro de Estudos Geográficos da Universidade de Lisboa e Assistente do Departamento de Geografia. E-mail: antlopes@mail.doc.fl.ul.pt

2 Investigador da área de Geo-ecologia do CEG e bolseiro do projecto CLIMLIS. E-mail: hugovieira@mail.vis.fl.ul.pt 


\section{INTRODUÇÃO}

Os estudos de climatologia urbana nas cidades portuguesas foram muito incentivados especialmente nos últimos quinze anos, desde que foi defendida a tese sobre o clima da região de Lisboa (AlCOFORADO, 1988). Os climas de outras cidades (Porto - MonTEIRO, 1993; Coimbra - GANHO, 1998; Évora - AlCOFORADO e TABORDA, 1998) e das áreas periféricas fortemente urbanizadas (Oeiras - LoPEs, 1994; 1998) foram pormenorizadamente monitorizados através de estações meteorológicas convencionais (pouco relevantes no estudo das variações locais dos parâmetros climáticos), mas sobretudo através de campanhas de medições itinerantes. De automóvel ou a pé, investigadores, professores e estudantes palmilham as ruas "da cidade», patrocinando verdadeiras "Semanas da Ciência»actualmente tão em voga e respondendo à natural curiosidade do "cidadão», que indaga o que se «anda a medir».

Os aparelhos utilizados evoluíram bastante desde que se começaram estas campanhas, nos anos oitenta, em Portugal. No início, os valores observados nos termómetros de mercúrio e nos psicrómetros de aspiração (do tipo Assmann), tinham de ser lidos em cada local, alongando o tempo total dos trajectos, que não deviam exceder uma hora para não gerarem confusão entre as variações espaciais termo-higrométricas e o seu ritmo diário.

Actualmente os modernos data loggers acumulam os valores de uma forma contínua e automática, já não sendo necessário recorrer à « folha de papel» para registar os dados, tornando mais eficientes as medições e permitindo recolher grandes quantidades de informação.

A prioridade na nossa investigação tem-se centrado no reconhecimento dos principais padrões climáticos (ilha de calor urbano, drenagem do ar frio, etc.), na sua aplicação no controlo da poluição (ANDRADE, 1996) ou no conforto (ANDRADE, 1998). No entanto, a maioria dos estudos de clima urbano nas cidades portuguesas são apenas representativos da camada atmosférica entre os prédios, a cerca de $2 \mathrm{~m}$ do solo, mostrando unicamente a repartição do fenómenos em duas dimensões ${ }^{3}$. Para se compreender os vários sistemas atmosféricos urbanos e a sua interacção com as superfícies, torna-se necessário medir os parâmetros climáticos em altura.

Os primeiros contactos com investigadores do Institut für Physische Geographie da Universidade Albert-Ludwig em Freiburg (Alemanha), em 1996, tornaram claro que a recolha de dados em perfil com balões cativos constitui uma boa técnica para se iniciar o reconhecimento do invólucro atmosférico que rodeia o espaço construído. A solução a que se chegou, e que é apresentada neste trabalho, é um compromisso entre os orçamentos, sempre insuficientes, e a necessidade de se obterem resultados minimamente fiáveis.

3 Com a excepção de lançamentos de balões estabilizados para reconhecer a estrutura da «ilha de calor» de Lisboa, efectuados por uma equipa suíça em colaboração com M. J. Alcoforado, em Agosto de 1987. 
Por outro lado, é preciso aplicar todos os conhecimentos, adquiridos com este e outros métodos. Mas o contributo que a climatologia pode dar ao planeamento urbano não se deve cingir ao reconhecimento dos padrões regionais e locais, sob pena de não se poderem transpor os conhecimentos para outras áreas urbanas, ou pura e simplesmente este saber, tão precioso, nunca poder ser aplicado (OKE, 1984). Utilizar os conhecimentos que, ao longo dos anos, se foram acumulando sobre o clima de Lisboa e generalizar os padrões microclimáticos de uma área para outra não é uma tarefa fácil e deve ser levada a cabo com extremo cuidado. Uma das tarefas do projecto CLIMLIS ${ }^{4}$ é a de tentar definir algumas das tipologias urbanas do norte da cidade de Lisboa (PINHO, 2002), condição necessária para se poderem exportar os resultados obtidos para outros locais com características morfológicas semelhantes. Da colaboração entre as várias equipas do projecto foi decidido escolher a zona de Telheiras como bairro «laboratório» para as primeiras experiências.

\section{OBJECTIVOS, TÉCNICAS E MATERIAL UTILIZADO}

A partir das técnicas, que a seguir se apresentam, é possível elaborar perfis térmicos em altura, dentro de espaços urbanos, embora se tenham efectuado algumas tentativas também em espaços abertos não construídos, nomeadamente no vale de Barcarena, em Oeiras. O material necessário para efectuar estes lançamentos é o seguinte:

\section{Balões Meteorológicos}

Em lançamentos de baixa altitude usam-se normalmente balóes do tipo zepelins. A principal vantagem reside na sua forma aerodinâmica, que permite uma mais eficaz adaptação à turbulência da camada atmosférica junto ao solo. Têm uma boa capacidade de transportar equipamento (mínimo de $2 \mathrm{~kg}$, segundo as empresas contactadas). O custo destes balões é a sua principal desvantagem, elevado demais para os nossos recursos financeiros. Acresce que também é necessário uma grande quantidade de hélio para se elevarem (os modelos mais pequenos têm um volume de $11 \mathrm{~m}^{3}$ ). Estes balóes são normalmente empregues em publicidade, o que poderá justificar o seu preço elevado.

Neste trabalho, recorreu-se à utilização de balões meteorológicos esféricos de 200 gramas, do tipo Totex (fig. 1), que foram enchidos com aproximadamente $1 \mathrm{~m}^{3}$ de «hélio ${ }^{5}$ standard» cada. Como são balóes preparados para sondar toda a

4 «Princípios climáticos para o planeamento urbano: aplicação a Lisboa».

5 Elemento químico (He), gás nobre inerte da tabela periódica, com o número atómico 2. É o segundo elemento mais leve, sem cor, inodoro e insípido (Encyclopaedia Britannica). Ao contrário do Hidrogénio, tem a vantagem de não ser inflamável, nem tóxico, apresentando, portanto, riscos reduzidos no seu manuseamento. 

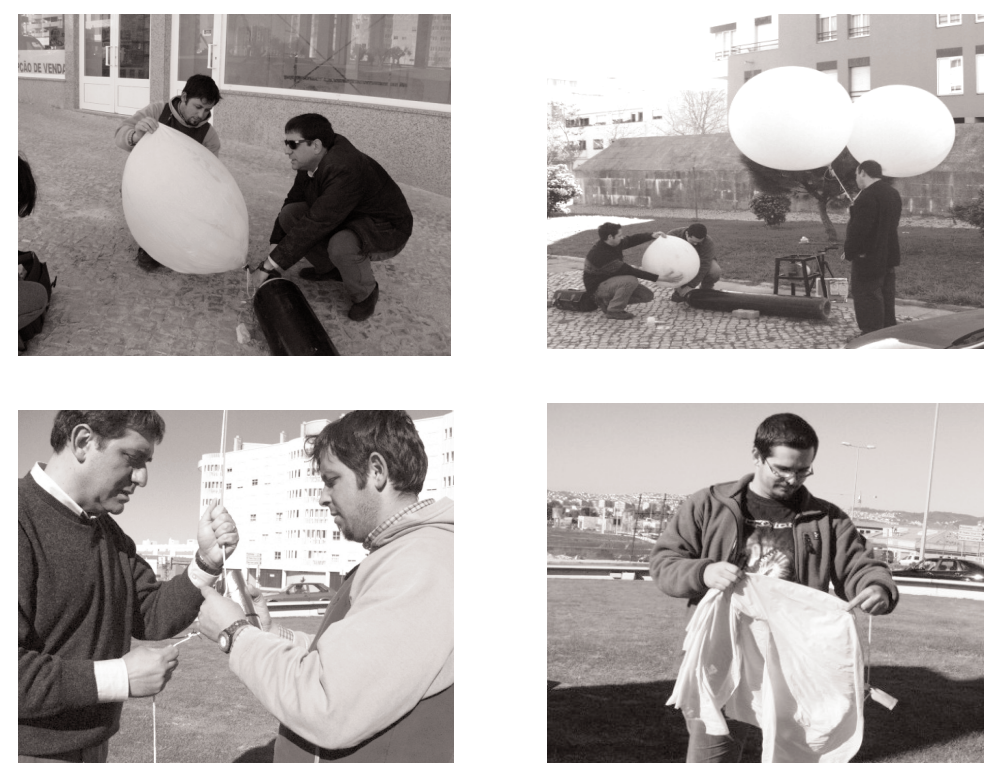

Fig. 1 - Enchimento dos balões cativos e colocação dos registadores térmicos (tinytalks).

Fig. 1 -Filling up the captive balloons and placing the tinytalks on the nylon rope.

troposfera e parte da estratosfera, até aproximadamente $20 \mathrm{~km}$ de altitude, muita vezes em condições extremamente adversas, são resistentes, mas concebidos para uma capacidade reduzida de equipamento transportado (cerca de $250 \mathrm{~g}$ ). Uma vez que o peso a suportar é superior, tiveram de ser utilizados 3 balões em cada lançamento, que se fixam ao solo por uma corda de nylon, resistente e leve, onde são presos os sensores (figs. 1 e 3). Este tipo de balão, pouco dispendioso e de fácil manuseamento, tem como principal desvantagem a sua forma esférica. Oferece maior resistência ao vento do que os zepelins, o que o torna apropriado em condições atmosféricas de vento inexistente ou fraco, tornando-se difícil efectuar lançamentos com ventos mais fortes. Os balóes são presos a uma estrutura metálica com uma roldana, que permite uma rápida subida e descida da corda.

Um dos principais problemas dos lançamentos é a manutenção da altura pretendida de cada aparelho registador; a turbulência não permite que a corda se mantenha sempre na vertical e, sobretudo durante as noites de arrefecimento radiativo, como aquelas em que se efectuaram medições, os balões têm tendência a descer um pouco, devido à existência de inversões térmicas baixas. É necessária uma vigilância constante para controlar a altura dos balóes. Durante o dia, pode medir-se a distância entre o local onde está presa a corda no solo e a vertical de cada um dos aparelhos. Conhecendo este valor e o compri- 
mento da corda entre cada sensor $(5 \mathrm{~m})$, determina-se, com alguma exactidão, a sua altura em cada momento (fig. 2). Para evitar que desçam durante a noite pode-se adicionar mais um balão.

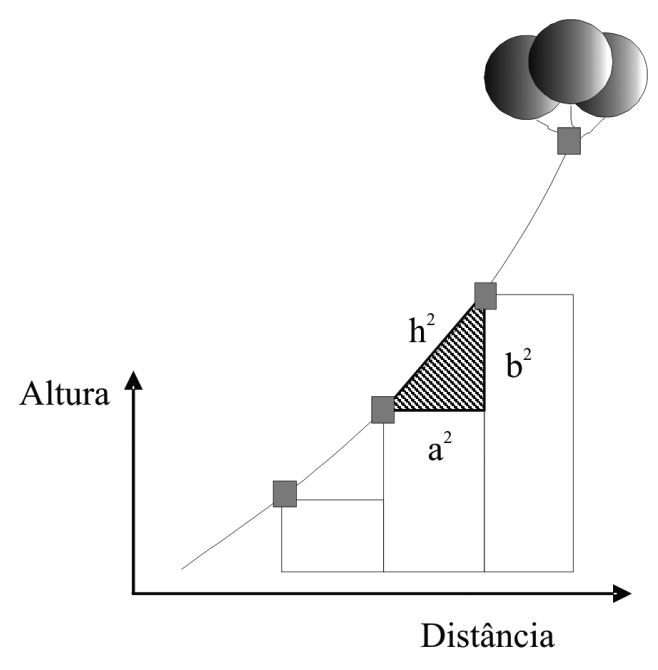

Fig. 2 - Esquema elucidativo da técnica de determinação da altura de cada aparelho.

Fig. 2 -This scheme shows an effective way to calculate the altitude of any tinytalk.

Será de referir que este tipo de lançamento, mesmo que efectuado a baixa altitude, carece de autorização das entidades reguladoras do espaço aéreo, sendo aconselhável a utilização de medidas adicionais de segurança, nomeadamente sinalização luminosa nos balões e uma sólida amarração, de modo a minimizar a probabilidade de eles se soltarem. Por causa do tráfego aéreo sobre a cidade, dever-se-á também consultar, entre outros, o Decreto 48542, de 24 de Agosto de 1968, onde é definida a servidão aeronáutica do Aeroporto de Lisboa.

\section{Registadores de temperatura}

Para a obtenção dos dados, foram utilizados pequenos registadores automáticos de temperatura, do tipo Tinytalk Data Logger. Estes aparelhos, que não chegam a pesar $100 \mathrm{~g}$ cada, têm a capacidade de armazenagem de 1800 valores medidos em intervalos pré-definidos (VIEIRA et al., 2000). De modo a proteger os aparelhos da radiação solar directa, foram construídos pequenos abrigos de material isolante e reflector (fig. 3).

As principais vantagens destes instrumentos são o baixo custo, a pequena dimensão, o peso reduzido, a simplicidade de adaptação para a tarefa que se 


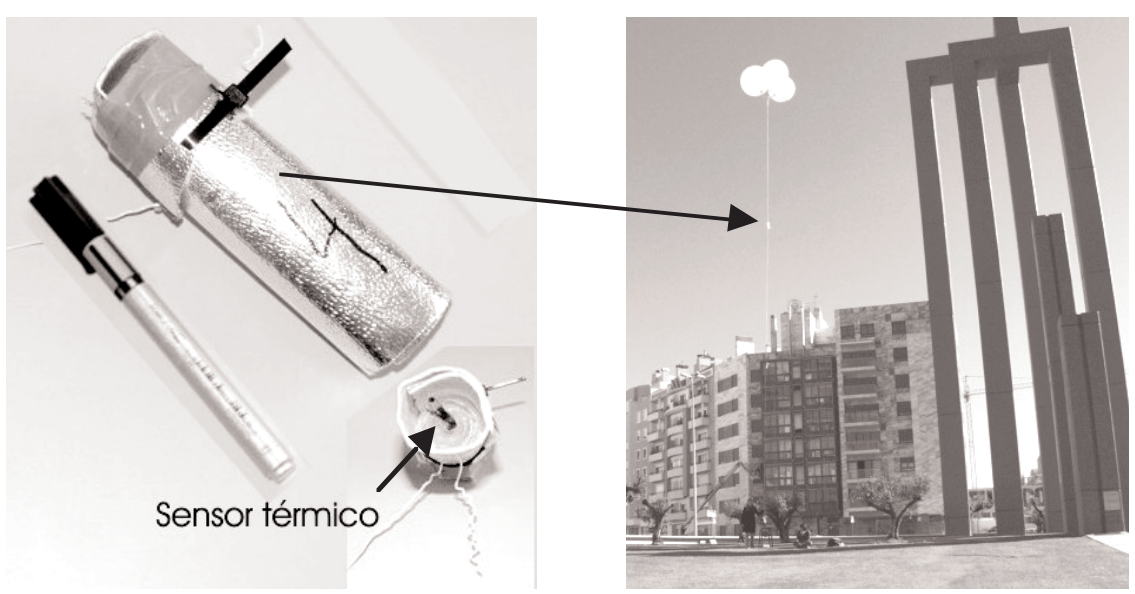

Fig. 3 - À esquerda o invólucro de protecção dos registadores térmicos (tinytalk). Primeiro lançamento dos balóes cativos em Telheiras, à direita (23 de Novembro de 2001).

Fig. 3 - On the left the tinytalk protection cover and on the right the first attempt to probe urban atmosphere with captive balloons (23 ${ }^{\text {rd }}$ November 2001).

pretende e a facilidade de manuseamento durante o descarregamento dos dados através de software próprio.

Na primeira campanha de medição foram colocados 3 aparelhos, de 5 em $5 \mathrm{~m}$, ao longo da corda que prende os balóes ao solo. Cada aparelho foi programado para armazenar um valor de temperatura de 5 em 5 minutos.

\section{Pequena estação meteorológica de referência}

Para completar o estudo microclimático do bairro escolhido e aferir os valores de temperatura, foi montada uma pequena estação meteorológica no local (no centro da rua). Os dados recolhidos em registo contínuo foram a velocidade do vento (o rumo foi observado várias vezes durante o período da campanha), a temperatura do ar a $2 \mathrm{~m}$ do solo e a humidade relativa. Infelizmente, devido a uma avaria, o termo-higrómetro apenas registou valores de temperatura entre a $1 \mathrm{~h}$ e $45 \mathrm{~m}$ e as $5 \mathrm{~h} 20 \mathrm{~m}$ (fig. 5). Ao mesmo tempo, foram obtidos os valores de radiação solar e terrestre com dois radiómetros. Um em pequeno comprimento de onda (piranómetro) e outro em longo comprimento de onda (pirgeómetro) (ANDRADE e LOPES, 1999; LOPES, 1999). Estes resultados não serão aqui discutidos, por não se enquadrarem no tema desta pequena nota, mas serão brevemente apresentados noutro local. 


\section{PRIMEIROS RESULTADOS}

A título de exemplo, apresentam-se os primeiros resultados da campanha de medições com balões cativos e registadores de temperatura, realizada em 23 e 24 de Novembro de 2001, na rua Professor António José Saraiva, em Telheiras, Lisboa.

Esta rua é praticamente fechada, apenas com duas pequenas entradas a Norte e a Sul (fig. 4) ${ }^{6}$. Durante o período de observações prevaleceu uma situação anticiclónica sem nebulosidade, com vento fraco de Nordeste $(<1,5 \mathrm{~m} / \mathrm{s}$ na estação Lisboa/Gago Coutinho e $<2 \mathrm{~m} / \mathrm{s}$ em Lisboa/Instituto Geofísico). Instalaram-se ainda dois registadores a cerca de $3 \mathrm{~m}$ de altura (tinytalk 1 e 2, fig. 4). $\mathrm{O}$ registador 1 ficou a $6 \mathrm{~m}$ da fachada do prédio a Este, enquanto o registador 2 ficou a $3 \mathrm{~m}$ da fachada do prédio a Oeste.

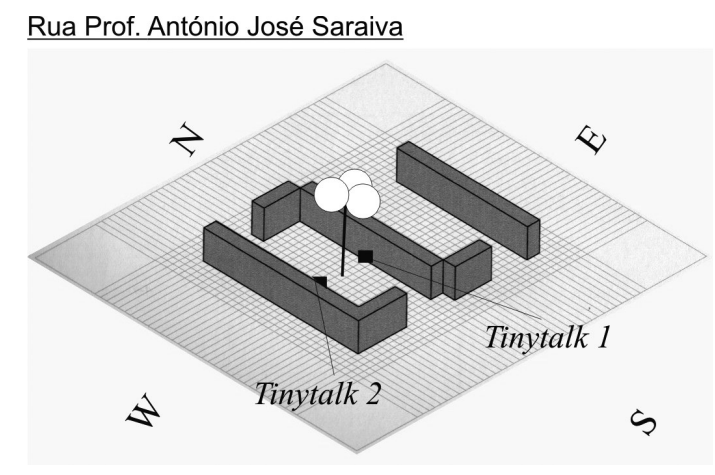

Fig. 4 - Local do primeiro lançamento no bairro de Telheiras (grelha $5 \times 5 \mathrm{~m}$ ). Na nota de rodapé 6 encontram-se as dimensões da rua e a altura dos prédios.

Fig. 4-The place of the first launchings in the Telheiras neighbourhood $(5 \times 5 \mathrm{~m}$ grid). In footnote 6 one can see the street and buildings dimensions.

O ritmo térmico no interior da rua (fig. 5) é nitidamente dependente do balanço radiativo: durante a tarde do dia 23 , o ar encontrava-se mais quente na parte superior do "canhão urbano» $(20 \mathrm{~m})$, enquanto a $10 \mathrm{~m}$ de altura, a temperatura era 1,5 a $3,5^{\circ} \mathrm{C}$ inferior. Note-se que, durante o mês de Novembro, o número de horas de Sol no interior desta rua é reduzido (pouco mais de 5 horas no local dos lançamentos), estando o solo e as fachadas dos prédios a maior parte do tempo à sombra, como se pode comprovar através dos diagramas solares representados na figura 6.

6 Esta rua, na verdade com uma estrutura de praceta quase fechada, tem uma largura de 56m e um comprimento de $110 \mathrm{~m}$ entre os edifícios que a limitam a Norte e a Sul. A altura dos prédios varia entre 20 e $26 \mathrm{~m}$. 


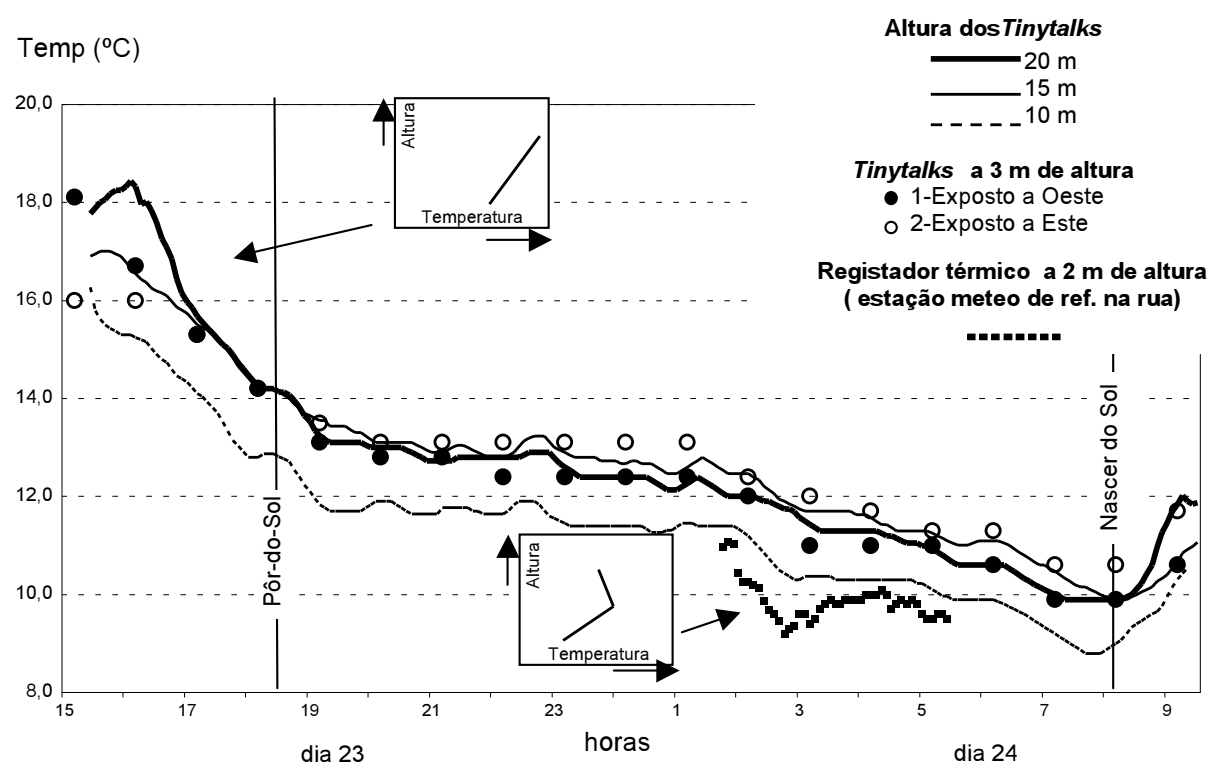

Fig. 5 - Evolução das temperaturas observadas em 23 e 24 de Novembro de 2001, na rua Prof. António José Saraiva.

Fig. 5 -Temperatures on the $23^{\text {rd }}$ and $24^{\text {th }}$ November 2001 in an urban canyon, northern part of Lisbon.
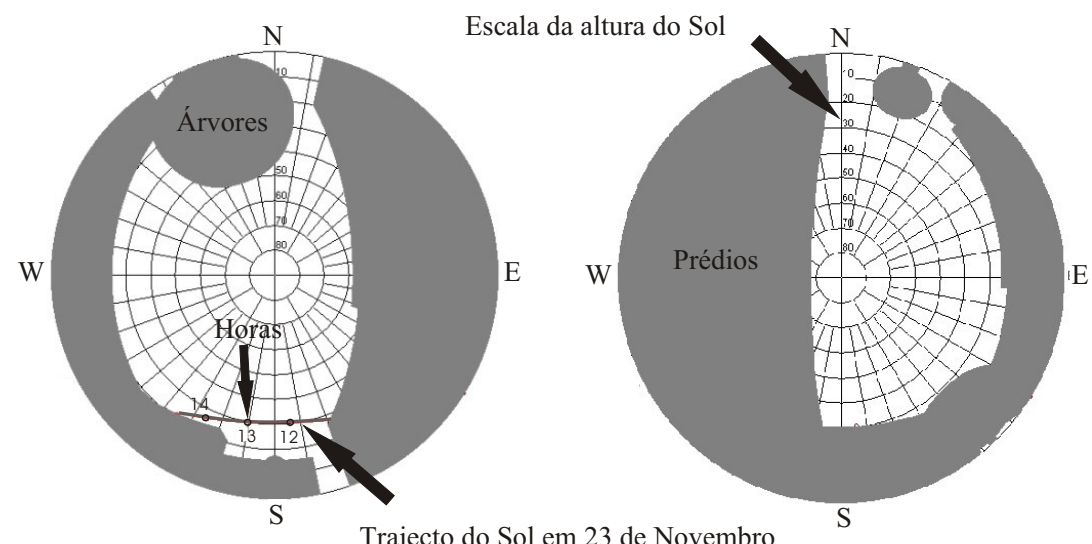

Tinytalk 1 exposto a Oeste

Tinytalk 2 exposto a Este

Fig. 6 - Diagrama polar para os locais de instalação dos tinytalk 1 e 2.

Fig. 6 - Polar diagram of the places where tinytalk 1 and 2 were installed. 
Algumas horas após o pôr-do-Sol as temperaturas mais elevadas verificavam-se a $15 \mathrm{~m}$ de altura, prolongando-se esta situação até ao início da manhã do dia 24. Conclui-se que se forma uma «bolsa» de ar ligeiramente mais quente no centro do "canhão urbano" durante toda a noite. Isto deve-se ao facto da superfície do solo arrefecer por irradiação infravermelha e o ar junto ao solo acompanhar esse arrefecimento. A comprová-lo estão as temperaturas mais baixas entre as 2 e as 5 horas da madrugada, observadas no registador térmico instalado no meio da rua, a $2 \mathrm{~m}$ do solo (fig. 5). A $20 \mathrm{~m}$ de altura, a temperatura mais baixa do que no nível inferior $(15 \mathrm{~m})$ justifica-se porque o registador se encontrava ao mesmo nível do topo dos edifícios e sofreu uma maior influência do vento que, embora muito fraco, soprava acima do nível dos prédios.

Para analisar a influência da exposição e a proximidade dos edifícios, foram colocados dois registadores a $3 \mathrm{~m}$ de altura (tinytalk 1 e 2 , figs. 4 e 6). Os dois aparelhos mostram comportamentos térmicos distintos (fig. 5): junto à fachada exposta a Este a temperatura durante a noite e manhã foi superior, podendo-se dar como hipótese a maior proximidade deste aparelho ao prédio que, durante a noite, fornece calor à atmosfera. Durante a tarde e até ao pôr-do-Sol a situação inverteu-se, registando-se os valores mais elevados no tinytalk 1 (exposto a Oeste), por receber maior quantidade de radiação solar.

Este comportamento térmico pode ser facilmente deduzido através da observação dos diagramas polares (fig. 6): exposto a Oeste, o tinytalk 1 (representado pelo centro do diagrama) está mais afastado dos prédios, recebendo um maior número de horas de Sol (mais de 5), do que o tinytalk 2, que se encontrou sempre à sombra. Por isso, na figura, a trajectória do Sol não aparece, por estar sob a projecção dos edifícios. Durante a noite, a temperatura medida pelo tinytalk 2 é mais elevada, devido à sua maior proximidade aos prédios.

O objectivo da presente nota era realçar a utilidade desta técnica nos estudos de microclimatologia urbana, que até agora, no nosso País, eram apenas baseados em observações a duas dimensões. Estes primeiros ensaios demostram a complexidade e variabilidade temporal da estrutura vertical da temperatura num «canhão urbano», neste caso traduzida numa «bolsa de calor» no interior de uma rua quase fechada. Estes resultados vão servir de ponto de partida para modelizar a relação entre a geometria dos «canhões urbanos» e a temperatura do ar e aplicar este conhecimento a outras tipologias urbanas, nesta e noutras cidades.

\section{AGRADECIMENTOS}

Agradecemos às Prof. ${ }^{\text {as }}$ Maria João Alcoforado e Suzanne Daveau a leitura e os comentários que permitiram melhorar esta nota, assim como ao Sérgio Oliveira, sempre disponível para ajudar nas campanhas de medição realizadas.

Esta investigaç ão enquadra-se no projecto «Princípios climáticos para o planeamento urbano. Aplicação a Lisboa: CLIMLIS», financiado pela Fundação para a Ciência e a Tecnologia, com comparticipação do FEDER (POCTI/GEO/ $34683 / 2000)$. 


\section{BIBLIOGRAFIA}

Alcoforado, M. J. (1988) - O Clima da Região de Lisboa. Vento, Insolação e Temperatura. Dissertação de Doutoramento em Geografia Física. Universidade de Lisboa (polic.: 568).

Alcoforado, M. J. e Taborda, J. (1998) - O clima de Évora. Contrastes térmicos locais. A cidade de Évora. Boletim de Cultura da Câmara Municipal, II série: 507-531.

ANDrade H. (1996) - A qualidade do ar em Lisboa. Valores médios e situações extremas. Finisterra - Revista Portuguesa de Geografia, Lisboa, XXXI (61): 43-66.

ANDRADE H. (1998) - O desconforto térmico estival em Lisboa. Uma abordagem bioclimática. Finisterra-Revista Portuguesa de Geografia, Lisboa, XXXIII (66): 41-58.

ANDRADE H. e A. Lopes (1999) - A influência da radiação e da velocidade do vento no conforto térmico na área suburbana a norte de Lisboa (Caneças). Actas do VIII Colóquio Ibérico de Geografia, Vol. I. Lisboa: 24-30.

Ganho, N. (1998) - O clima urbano de Coimbra: estudo de climatologia local aplicada ao ordenamento urbano. Universidade de Coimbra (polic.: 501).

Lopes, A. (1994) - Padrões Térmicos do Clima Local na Região de Oeiras, Dissertação de Mestrado em Geografia Física e Regional. Universidade de Lisboa (polic.: 220).

Lopes, A. (1998) - Contrastes térmicos nocturnos e acumulação de ar frio em áreas urbanas do sul da península de Lisboa. Finisterra-Revista Portuguesa de Geografia, Lisboa, XXXIII (66): 25-40.

Lopes, A. (1999) - O balanço de radiação e as temperaturas num vale da Região de Lisboa (Barcarena): elementos para o planeamento urbano. Actas do VIII Colóquio Ibérico de Geografia, Vol. I. Lisboa: 45-51.

Monteiro, A. (1993) - O clima urbano do Porto. Contribuição para a definição das estratégias de planeamento e ordenamento do território, Dissertação de Doutoramento em Geografia Física, FLUP. Porto (polic.: 436).

OKE, T. R. (1984) - Towards a prescription for the greater use of climatic principles in settlement planning. Energy and Buildings, 7: 1-10.

OKE, T. R. (1993) - Boundary layer climates. Routledge, London: 435.

Pinho, A. C. (2002) - Bairro de Telheiras - tipologias de implantação. Projecto CLIMLIS/ Núcleo de Arquitectura do LNEC, inédito.

Vieira, G.; Mora, C. e Ramos, M. (2000) - Registadores automáticos de baixo-custo para a monitorização de temperaturas do ar, rocha e solo. Finisterra-Revista Portuguesa de Geografia, Lisboa, XXXIV (69): 139-148. 